\title{
TWO HUNDRED YEARS OF THE FOXGLOVE
}

\author{
by
}

\author{
SUSAN WRAY, D.A. EISNER, AND D.G. ALLEN*
}

\section{INTRODUCTION}

1985 marks the bicentenary of the publication of William Withering's account of his studies on the clinical use of digitalis. ${ }^{1}$ The first part of the present article reviews the use of digitalis before Withering and also the impact that his work had on the use of digitalis in the next hundred years or so. The final two sections deal with work in the present century concerning the clinical use of digitalis and also its mechanism of action. It will become clear that, although an enormous amount of work has been done since Withering, both the therapeutic use and the mode of action are still controversial.

DIGITALIS BEFORE WITHERING'S MONOGRAPH IN 1785

Digitalis purpurea was so named in 1542 by Leonhard Fuchs. It was certainly known and used before the Withering monograph was published. Ointments containing digitalis are mentioned in the Welsh pharmaceutical book Meddygon Myddmacn around 1250, as being good for headaches and spasms. Digitalis pills are described in Hieronymus Bock's Book of herbs (1546). In England, digitalis was recommended by John Parkinson (1567-1650) and William Salmon (1644-1713) for treatment of epilepsy, goitre, and tuberculosis, and as an expectorant and an emetic. Salmon published several works on medicinal plants and in one ${ }^{2}$ mentioned digitalis as providing therapy for dropsy, a disease involving a generalized accumulation of fluid now regarded as a symptom of heart failure. It was included in the Pharmacopoeia Londinensis (1650).

However, before Withering's account, digitalis had fallen almost into disuse. This was largely due to reports of the toxic nature of the drug when taken by mouth. For example, François Salerne in $\mathbf{1 7 4 8}$ gave a lecture to the French Academy in Paris, which seems to be the first account of animal experiments using digitalis. ${ }^{3} \mathrm{He}$ described how, after administering digitalis leaves to turkeys and roosters, the animals appeared drunk, had fits, and died. He cautioned "on voit par ces experiénces le dérangement que l'usage de cette plante peut causer dans les organes

\footnotetext{
*Susan Wray, D.A. Eisner, and D.G. Allen, Department of Physiology, University College London, Gower Street, London WC1E 6BT.

1 William Withering, An account of the foxglove and some of its medical uses: with practical remarks on dropsy and other diseases, Birmingham, 1785.

2 W. Salmon, Botanologia: the English herbals; or history of plants, London, 1710, p. 399.

${ }^{3}$ François Salerne, 'Observation de botanique', Histories de l'Académie Royale des Sciences, Paris, 1748 , pp. $120-122$.
} 
de ces animaux". Shortly before, Herman Boerhaave (1668-1738) had considered digitalis too toxic. ${ }^{4}$

WILLIAM WITHERING (1741-99)

William Withering (plate 1) was born in Wellington, Shropshire, the second child and only son of Edmund and Sarah Withering. His father was an apothecary, who also had private means from an inheritance and had married well, as Sarah was the daughter and sister of physicians. ${ }^{5}$ After local schooling William went to medical school in Edinburgh in 1762. He appears to have enjoyed Edinburgh, and read papers to the student medical society, including one on dropsy. He received his diploma in 1766, with a thesis dissertation on 'Malignant putrid sore throat'. After spending a few months in Paris, and visiting his family in Wellington, he started medical practice in Stafford, which is only about twenty miles from his home town. At this time (1767), the Staffordshire Infirmary was started, with Withering and Dr Archibald Campbell as the first two physicians. During his first year in Stafford, Withering treated Miss Helena Cookes, an attorney's daughter. Helena drew and painted flowers, and Withering started collecting specimens for her. They were married in September 1772. Matrimony stimulated Withering to look for a practice which would bring him more income. He left Stafford for Birmingham in 1775. His practice at 9 Temple Row increased steadily in size to become one of the largest outside London, producing an income of $£ 2,000$ per annum. He became one of the most successful physicians of his day, treating well-to-do and titled people along with his free consultation periods for the poor. For example, Benjamin Franklin, when in Paris, requested advice from Withering for treatment of a stone in the bladder.

Around this time (May 1776) Withering's two volumes entitled The botanical arrangement of all the vegetables naturally growing in Great Britain ${ }^{6}$ were published. Linnaeus had published his Genera et species plantarum in 1736, and Withering's work was the first comprehensive English publication based on the Linnaean system. Apparently, Withering thought that the terms used to describe the sexual characteristics of plants, which form the basis of the Linnaean system, were too explicit considering the many ladies who were attracted to botany. He therefore used the terms "pointal" for pistil and "chive" for stamen. Interestingly, Withering said little about the medical attributes of plants, since he considered that too few facts were available to warrant inclusion. Under foxglove, he said "a dram of it taken internally excites violent vomiting. It is certainly a very active medicine and merits more attention than modern practice bestows on it." Withering started collecting his case histories for his account of the foxglove in 1775, i.e., just a year before these volumes were published. It is probable that Withering considered these botanical volumes his chief work. It was undoubtedly successful-a fourteenth edition

4.H. Garrison, An introduction to the history of medicine, Philadelphia and London, W.B. Saunders, 1929, pp. 315-317.

${ }^{5}$ T.W. Peck and K.D. Wilkinson, William Withering of Birmingham. Bristol, John Wright, 1950. For a discussion of the social status of apothecaries in eighteenth-century England, see J.G.L. Burnby, $A$ study of the English apothecary from 1660 to 1760, (Medical History, supplement no. 3), London, Wellcome Institute for the History of Medicine, 1983, pp. 92-112.

'William Withering, The botanical arrangement of all the vegetables naturally growing in Great Britain, Birmingham, 1776. 


\section{Susan Wray, D. A. Eisner, and D. G. Allen}

appearing just over a hundred years later (1877). His reputation as a botanist spread all over Europe and he was member of the Linnaean Society. The plant, Witheringia solanacea, is named after him.

Withering had many other scientific interests. He was a scholar of geology, presenting papers to the Royal Society on rocks and soil. Indeed, because of his work distinguishing barium carbonate from barytes (barium sulphate), Werner, a German chemist, in 1796 named barium carbonate as Witherite. Withering also analysed spa water from various sources, including the famous hot springs at Caldas in Portugal, for which he was awarded honorary membership of the Royal Academy of Portugal. Withering, who suffered for a large part of his life from consumption, was in Portugal to escape the English winter and convalesce. At the age of fifty-eight, on 6 October 1799, he died.

\section{WITHERING AND THE FOXGLOVE}

In 1775, Withering started collecting case histories on the effects of digitalis in dropsy and ascites (accumulation of fluid in the abdomen). But what had led him to start using internal applications of digitalis at a time when it was little used because of reports of toxic effect? Withering himself explained this in his account.

In the year 1775, my opinion was asked concerning a family receipt for the cure of dropsy. I was told it had long been kept a secret by an old woman in Shropshire, who had sometimes made cures after the more regular practitioners had failed and was informed that the effects produced were violent vomiting and purging; for the diuretic effects seemed to have been overlooked. The medicine was composed of 20 or more different herbs.

He examined the dried leaves microscopically. (His botanical volume contained an account and a picture of the microscope he had designed for the study of botany.) In this way, he noted that the foxglove leaf was present, writing "It was not very difficult for one conversant in these subjects, to perceive, that the active herb could be no other than the foxglove". He determined, therefore, to investigate the effects of digitalis. And he continued that, after noting a few cases, "I ventured to assert in the Botanical Arrangement published the following spring that Digitalis purpurea merited more attention than modern practice bestowed upon it". Withering made notes on his animal experiments, for which, like Salerne, he chose the turkey. His first patients were the poor, who came for advice during his one hour a day which was free of charge. He observed the very powerful diuretic effect of digitalis, but added, "I gave it in doses very much too large and urged its continuation too long". He said that he did not introduce it into his more regular mode of prescription until he heard that Dr Crawley, the principal of Brasenose College, Oxford, had been cured of a hydrops pectoris by foxglove root. Withering included in his account 163 cases he had treated, plus others reported to him by physicians whom he had instructed in its use. He reported all his cases, and so noted that digitalis did not successfully treat all maladies involving accumulation of fluid. The cases of dropsy which he described as having responded well to digitalis were those with the symptoms of atrial fibrillation with oedema. A distinction between dropsy from circulatory or kidney disease was made later by Richard Bright (1789-1858).

Apart from these clinically important details, the most significant point in Withering's book was his attention to dosage. Since the therapeutic dose of digitalis is 


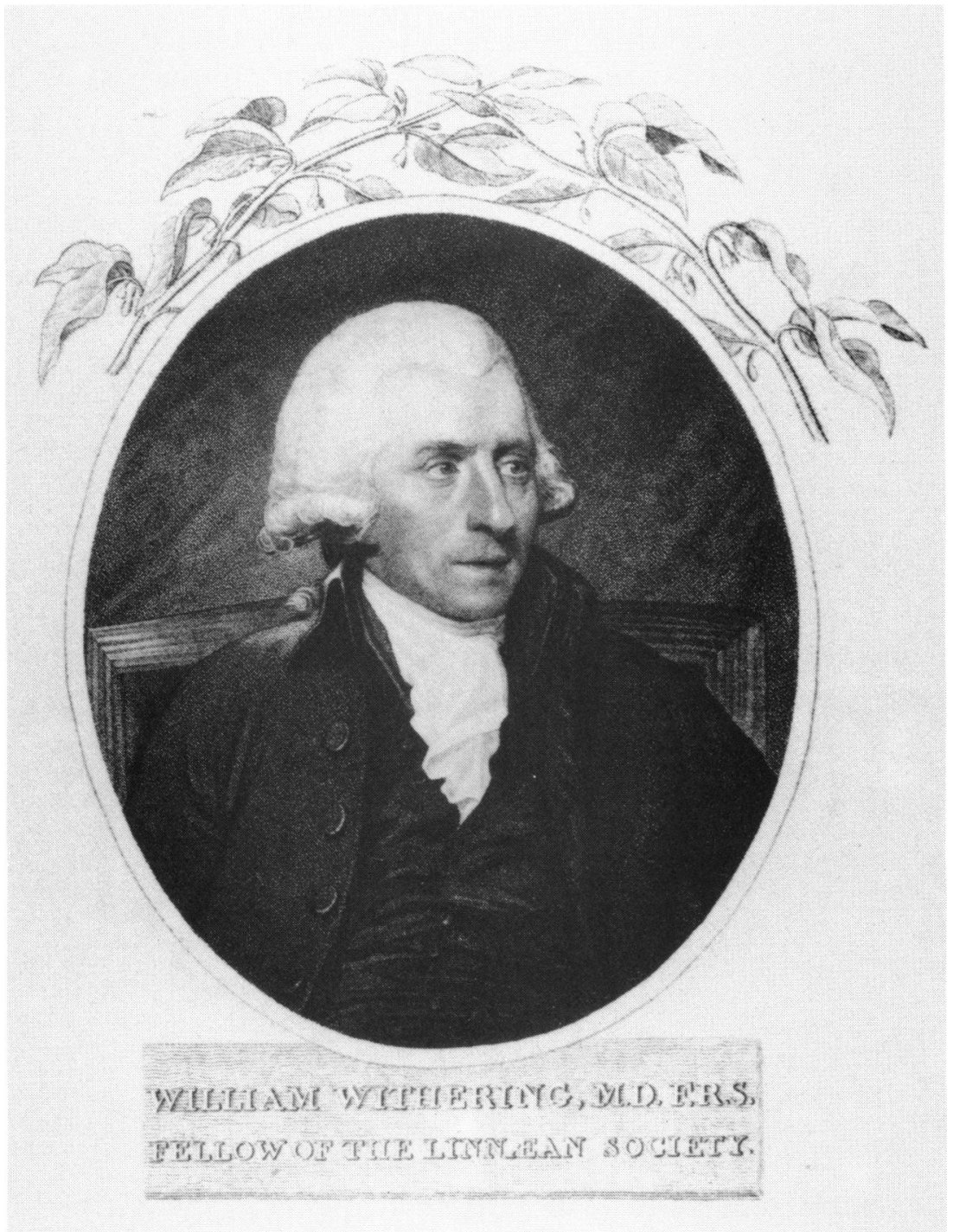

Plate 1. Portrait of William Withering. From an engraving of William Bond after a painting by Carl Frederik von Breda (1792). 


\section{Two hundred years of the foxglove}

round sixty per cent of the toxic dose, digitalis has one of the lowest safety margins for a prescribed drug. Withering's account gave details of when to collect the leaves, noting that one could not trust the root of a biennial plant. He gave exact measurements for making digitalis infusions, i.e., 1 dram of the dried leaf infused with a half-pint of boiling water for four hours and an ounce of any spiritous liquid to be added. The dosage for an adult was an ounce twice daily. Withering devoted many pages to effects, rules, inferences, and cautions on the use of digitalis leaf. He explained that there was no need to bring on sickness and purging, rather to give the initial dose, wait long enough for it to take effect, and continue until it acted on the kidneys, stomach, pulse, or the bowels; then let it be stopped upon the first appearance of any of these effects. Although undoubtedly Withering was advocating digitalis because of its diuretic effect, he did draw attention to the cardiac action of the drug. He noted how "attention to the state of the pulse" should be made and that "it [digitalis] has a power over the motion of the heart, to a degree yet unobserved in any other medicine, and that this power may be converted to salutary ends". He thought that slowing of the heart was as much a side-effect of digitalis as the nausea and vomiting. He also stated that, "if the [patient's] pulse be feeble or intermitting" the drug would effectively relieve dropsical symptoms. Withering's correspondence with Hall Jackson in America demonstrates how cognizant he was of the action of digitalis. In February $1786,{ }^{7}$ Hall Jackson requested a supply of foxglove seeds as the plant was unknown in his vicinity (New Hampshire); in his reply, Withering described how he had cured three cases of haemoptoe which "were the kind with a quick-bounding pulse and I directed the medicine [digitalis] from the quality I knew it possessed of abating the action of the heart". No other manuscript from Withering on this subject is known. It seems, therefore, that we must conclude that Withering's most important contributions on digitalis were to revive interest in the drug and lay down guidelines for dosage and treatment. It is worth remembering that before Withering's account, dropsy was almost always a fatal disease.

\section{DIGITALIS AFTER WITHERING'S ACCOUNT}

Withering's writing undoubtedly sufficiently stimulated physicians of the time to try digitalis as a cure for dropsy. The most publicized report was that of Dr John Coakley Lettsom (1744-1815). In 1773, at the age of twenty-nine Lettsom had founded the Medical Society of London and had been elected to the Royal Society. In 1788, he published the results of his own unsuccessful experiences with digitalis. ${ }^{8}$ Among Lettsom's eight patients was Charles James Fox, the statesman, who was suffering from cirrhosis, and in whom digitalis apparently proved fatal. ${ }^{8}$ Withering pointed out to Lettsom that he used both too large a dosage and did not choose those with "constitutions favourable to the drug". "There does not, however, appear to have been any animosity between the two men, since Lettsom wrote to Withering inviting him to become a provincial member of the Medical Society of London. Withering

\footnotetext{
7 J. Worth Estes, Hall Jackson and the purple foxglove, Hanover, New Hampshire, University Press of New England, 1979, p. 207.

8 John Coakley Lettsom, 'Of the digitalis purpurea, in hydropic diseases', Mem. Med. Soc. Lond., 1794, 2: $145-180$.

${ }^{9}$ Peck and Wilkinson, op. cit., note 5 above, pp. 82-83.
} 


\section{Susan Wray, D. A. Eisner, and D. G. Allen}

accepted and received his diploma of the society in 1787. Sir George Baker (1722-1809), a physician to King George III, reported a case of the successful use of digitalis in dropsy. Physicians in Withering's vicinity (Birmingham) were also reporting their experiences with digitalis. The surgeon William Jones noted that the foxglove reduced the pulse in his patients, and a Mr Mynors (another Birmingham surgeon) recommended it "with a view to diminish the increased action of the heart, and the whole of the vascular system". ${ }^{10}$ Thus it is possible that Withering and Birmingham's doctors were coming to think more of digitalis acting on the heart. Tangential evidence is supplied in a poem about the drug, written by Miss Sarah Hoare (1767-1855) in 1818. Miss Hoare's father had been treated with digitalis, for congestive heart failure.

The Foxglove's leaves, with caution given,

Another proof of favouring Heav'n,

Will happily display;

The rapid pulse it can abate;

The hectic pulse it can moderate;

And blest by Him whose will is fate,

May give a lengthened day.

With, or more probably without, understanding the basic action of digitalis, clinicians were gaining experience with it as a result of Withering's work. After Withering's publication, the first attempt to see how digitalis affects the body appears to be that undertaken by Thomas Beddoes (1760-1808) and his surgical colleague, Mr King. Beddoes published a report in 1794, demonstrating that opium counteracted digitalis toxicity. ${ }^{11} \mathrm{He}$ performed experiments on frogs and toads, applying digitalis to the skin, and observed initial excitement followed by inactivity. From these observations and his clinical experience, Beddoes concluded that digitalis would increase the action of the arterial system and that it increased the organic action of the contractile fibres as much or more than opium. There was much debate at this time as to whether digitalis was a sedative, inducing sleep and diminishing the pulse, or a stimulant, producing diuresis and purging.

John Ferriar (1761-1815) recognized that digitalis's primary action is on the heart. Ferriar, another Edinburgh graduate and a Manchester physician, in a monograph on digitalis in $1799,{ }^{12}$ reported how the foxglove retards the velocity of the pulse, reducing it, "without danger from 120 in a minute to 75 or 80 ". He said what great difficulty there is "respecting the theory of the action of digitalis ..." and that "I feel it impossible to explain this phenomenon at present. The diuretic power of digitalis does not appear to me a constant and essential quality of the plant; the power of reducing the pulse is its true characteristic." He continued "the secreting vessels of the kidnies are, in general, affected by stimulants, which act upon the whole of the

${ }^{10}$ Estes, op. cit., note 7 above, p. 172.

${ }^{11} \mathrm{~T}$. Beddoes, 'An account of the good effects of opium in the case of a person poisoned by digitalis', Medical Facts and Observations, 1794, 5: 17-20.

${ }^{12}$ John Ferriar, An essay on the medical properties of the digitalis purpurea or foxglove, Manchester, 1799 , p. 4. 


\section{Two hundred years of the foxglove}

blood-vessels; but it is conceivable, that a spasmodic state of the vessels secreting urine, or a diseased action in them may be overcome by a remedy, which lessens the force of the general circulation." And again, "I have had occasion to mention, formerly, the utility of digitalis in palpitations of the heart and have known it to remove the complaint entirely ... even in cases depending on organic laesions of the heart ... and rendered life not only longer, but more supportable ... and in one remarkable case of [of dropsy] ... the vigour and steadiness of the pulse increased, exactly in proportion as the water was withdrawn from the cellular membrane."

As an index of the interest and knowledge of digitalis, the Medical and Physical Journal of London, vol. 3 in 1800, had nine papers on the foxglove. Medical writers were taking account of digitalis. Thus John Murray wrote in his textbook of materia medica (1804), "of all narcotics, digitalis is that which diminishes most powerfully the action of the system; and it does so without occasioning any previous excitement. Even in the most moderate dose it diminishes the force and frequency of the pulse ... it is one of the most certain diuretics in dropsy apparently from its power of promoting absorption." ${ }^{13}$ Kreysig of Saxony in 1814, also postulated a direct effect of digitalis on the heart and blood vessels. However, he assumed that the slowing of the pulse originated in the brain. Johann Evangelista Purkinje (1787-1869), Professor of physiology at Breslau and Prague, described arrhythmias and optical sensation upon the self-administration of foxglove leaves.

An assessment of Withering's publication thirty years on is provided by Dr. John Blackall (1771-1860), who published his own observations on patients with dropsy, including the fact that there is often albumin in the urine. ${ }^{14}$ He stated "This plant [foxglove] has certainly made a great addition of late years to our means of cure. For although before the time of Dr. Withering's publication on that subject it has been employed very frequently both in this and other countries as a domestic drug, yet its exhibition was regulated by no sort of principle or distinction and accuracy, as to dose, was wholly out of the question."

The story of digitalis now turns partly into one of declining use. For reasons that are not entirely clear, digitalis became less favoured clinically, although experimental observation continued to be made. One explanation for the decline in clinical usage of digitalis given by Holmstedt and Liljestrand is "the general nihilistic view of therapeutics" which prevailed in the nineteenth century. ${ }^{15}$ Estes suggests that, because clinicians at that time believed that dropsy and consumption had very similar pathologies, and consumptives were treated with foxgloves with disappointing results, then faith in digitalis to cure dropsy was shaken. ${ }^{16}$ This suggestion is amplified by Ackerknecht, who notes how new drugs, such as digitalis, quinine, and iodine, quickly come to be regarded as panaceas. ${ }^{17}$ As digitalis became used far more often for conditions it could not improve (fevers, epilespsy, scrofula, goitre, nymphomania), this led to scepticism about its use for any condition.

${ }^{13}$ John Murray, Elements of materia medica and pharmacy, Edinburgh, A. Neill, 1804, pp. 131-300.

14 John Blackall, Observations on the nature and cure of dropsies, London, Longman Hurst, Rees, Orme \& Brown, 1818, pp. 300-302.

${ }^{15}$ B. Holmstedt and G. Liljestrand, Readings in pharmacology, Oxford, Pergamon Press, 1963, p. 57.

${ }^{16}$ Estes, op. cit., note 7 above, p. 231.

${ }^{17}$ Erwin H. Ackerknecht, 'Aspects of the history of therapeutics', Bull. Hist. Med., 1962 36: 389-419. 
Influential physicians, for example Corvisart (1755-1821) and his pupil Laënnec (1781-1826), both dismissed digitalis. Clinicians were also starting to forget Withering's insistence on small doses and thus eliciting toxic effects with the drug. Jawetz has postulated that all drugs go through an initial period of "enthusiasm", followed by "disappointment" and then a "final stabilization" ${ }^{18}$ In the nineteenth century, speaking in general terms, digitalis was definitely in the "disappointment" phase, although important experimental observations were made. Jean-Baptiste Bouillaud (1796-1881) published his Traité clinique des maladies du coeur based on auscultation in $1835 .{ }^{19} \mathrm{He}$ described digitalis as "le grand moderateur, cette sort d'opium du coeur". Ludwig Traube (1818-76) was a pupil of Purkinje and a clinician in Berlin, who has been credited with imparting new momentum to the study of digitalis. By 1850, he had recognized the increase in efficiency of cardiac muscle under the influence of digitalis. He further suggested that the digitalis-induced bradycardia (slowing of the heart) was a result of vagal stimulation. In 1854, Homolle and Querenne published their effort to make purer extracts of digitalis. ${ }^{20}$ Vulpian, in 1855, was the first to use animal experiments to elucidate the action of digitalis, rather than just to observe the symptoms induced. In frog heart, he showed a slowing of the auricles and muscular contracture of the ventricles. However, the notion that digitalis must act as a "sedative" still persisted, making it difficult to understand its therapeutic value. Then, in 1870, G.W. Balfour of Edinburgh argued that digitalis strengthened the heart and that its action could not be entirely sedative. Milner Fothergill, the next year, said "increased ventricular contraction is the action par excellence of digitalis". ${ }^{21}$ Diuresis in clinical cases he ascribed to an amelioration of the condition of the circulation. By the beginning of the twentieth century, Elijah Houghton had introduced the standardization of digitalis preparations in the frog. At the end of the nineteenth century, the direct effect of cardiac glycosides (a name given by Gerhardt in 1852) on cardiac contractility was still being overlooked by many investigators, who were more concerned with alterations of rhythm, role of the vagus, and the systolic contracture seen in amphibian hearts. But it was then realized that the heart was the site of digitalis action and the diuresis was a secondary effect. Purer forms of digotoxin were also made. As an example of thinking on digitalis in the 1880s, Karl Binz's (1832-1912) lecture notes of 1884 can be consulted. ${ }^{22}$ Binz stated that the force of a single contraction of the ventricle can be four to six times greater than normal in digitalis-treated animals. He said how Ludwig Traube referred to this increased action being due to stimulation of the excito-motor nerves, but Binz made the salient point that the result is essentially the same in an isolated heart. He continued, "we know now that digitalis chiefly acts, not by lowering the action of the heart, but by regulating and strengthening it, and that consequently the diminished frequency of the pulse is only a symptom of minor importance." The differential

\footnotetext{
${ }^{18}$ Ernest Jawetz, 'Infectious diseases: problems of antimicrobial therapy', Ann.Rev.Med., 1954, 5: 1-26.

19 J.-B. Bouillaud, Traité clinique des maladies du coeur, Paris, 1835.

${ }^{20} \mathrm{E}$. Homolle and T.A. Querenne, Mémoire sur la digitaline et la digitale, Paris, 1854.

21 J.M. Fothergill, Digitalis: its mode of action, London, 1871.

${ }^{22}$ Karl Binz, Lectures on pharmacology for practitioners and students, London, New Sydenham Society, 1895 , vol. 154 , pp. $242-260$.
} 


\section{Two hundred years of the foxglove}

effect on dropsy due to heart and kidney disease was also known by then. "The effect which digitalis has of equalising the circulation and of removing a state of passive congestion of the kidneys is an important indication for its use as a diuretic. It only acts as such in those cases in which the decrease of the urine, and the dropsy; depend on some heart mischief. Digitalis has no direct action upon the kidney tissue."

In contrast to the interest in the mechanism of action of digitalis, its therapeutic use had not advanced during the nineteenth century. This caused Cushny to write in 1922 , "what was written by its [digitalis] advocates in 1810 might have been quoted as representing the general view in 1900 . Those who wish to follow the sterile discussions of this period will find some account of them in Meyer's 'Digitalistherapie'", and "the physician... continued to prescribe digitalis in disease of the heart after the manner of his father and perhaps with less discrimination than his grandfather." ${ }^{23}$

\section{CLINICAL USE OF DIGITALIS IN THE TWENTIETH CENTURY}

By the beginning of the twentieth century, digitalis was established as the mainstay of the treatment of cardiac failure. Its use for most of the other diseases for which it had been promoted during the nineteenth century had been discarded. Changes in the clinical usage of digitalis during the present century have been relatively modest and the purified active principle from digitalis is still used, or at least given a trial, in virtually all cases of heart failure. Because cardiac failure is a common disease and because a cardiac glycoside is often prescribed indefinitely, the cardiac glycosides have become the fourth in the list of most commonly prescribed drugs in the US. ${ }^{24}$

\section{Formulation of digitalis products}

During this century, substantial progress has been made in the formulation of digitalis products. Withering tried a variety of different ways of extracting and storing the active principle and finally made the greatest use of the alcoholic extract or tincture. At the beginning of this century, this practice was gradually being superseded by the use of pills made from powdered digitalis leaf. Naturally, the potency of such tinctures and pills showed great variations, and this meant that the correct dose had to be found by experiment in every patient and that the process had to be repeated whenever one batch of pills or tincture was consumed. An important development, therefore, was the introduction of biological standardization procedures by Houghton in $1886 .{ }^{25}$ His procedure involved the injection of gradually increasing doses of digitalis into the lymph sac of a frog. The smallest dose which arrested the heart under specified conditions was called a frog-unit. This unit proved rather variable, and the seasonal nature of frogs caused problems, so that a more satisfactory cat-unit was soon introduced. ${ }^{26}$ Pharmaceutical houses were quick to see the advantages of these procedures and were soon marketing products which had been standardized to contain a specified number of cat-units.

\footnotetext{
${ }^{23}$ Arthur R. Cushny, The action and uses in medicine of digitalis and its allies, London, Longmans, Green, 1925, p. 208.

24 D. Schick and J. Scheuer, 'Current concepts of therapy with digitalis glycosides', Amer. Heart J., 1974, 87: 253-258.

${ }^{25}$ E. Houghton, 'The pharmacologia assay of heart tonics', J.Amer.Med.Ass., 1898, 31: 959-961.

${ }^{26}$ See discussion in Cushny, op. cit., note 23 above.
} 


\section{Susan Wray, D. A. Eisner, and D. G. Allen}

Active efforts were made throughout the nineteenth century to obtain the purified active ingredients of digitalis extracts. Although Homolle and Querenne won the prize of 1000 francs offered by the Sociéte de Pharmacie in 1845 for the production of a purified crystalline extract which they called digitaline, ${ }^{27}$ Cushny in 1904 stated "digitaline of commerce varies much in composition and in dose, sometimes proving entirely inert, while at other times it has proved poisonous in comparatively small quantities". ${ }^{28}$ Not until the 1920 s and ' 30 s did the purified preparations of the main active ingredients, digoxin and digitoxin, become available in a sufficiently reliable form for them gradually to supersede the cruder extracts. Digoxin and digitoxin are now the main products used and they are available in sufficient purity to have obviated the need for biological assay. Nevertheless, they are still extracted from foxglove leaves. In the last decade, it has also become possible to measure serum levels easily and cheaply, and this has led to a better understanding of the absorption, metabolism, and excretion without, however, leading to any pronounced changes in clinical practice. ${ }^{29}$

\section{The value of cardiac glycosides for patients in sinus rhythm}

Although the indications for the use of cardiac glycosides have not, in fact, changed dramatically during this century, there have been many investigations and much debate particularly on the question of the value of cardiac glycosides in patients with cardiac failure who are in sinus rhythm. Research in this area has been stimulated by a rapid increase in the understanding of cardiac arrhythmias, particularly at the turn of the century when the electrocardiograph was developed ${ }^{30}$ and introduced to clinical practice. ${ }^{31}$ In addition, the gradual development of the clinical trial has offered an objective means of assessing the relative values of different drug treatments or of assessing the relative value of the same drug treatments but in differing clincial situations.

The first edition of Cushny's Textbook of pharmacology (1904) described the major therapeutic value of digitalis as "counteracting certain changes in the circulation which result in blood accumulating in the veins in large quantities". ${ }^{32}$ The mechanism of action of the drug was the "increased contraction of the ventricles and auricles in systole". This view is backed by a number of original records of contraction of frog and dog hearts (e.g., fig. 1) under the influence of digitalis and by an extensive bibliography. Cushny's views on the indications for glycosides and the mechanism of action are suprisingly similar to those current today. He was adamant that the beneficial effects of digitalis were not directly attributable to the slowing of the heart, on the grounds that drugs which simply slowed the heart by an action on the vagus had no such beneficial effect. This is in direct contrast to the ideas promulgated several decades later by Thomas Lewis, who persistently, but with little

\footnotetext{
${ }^{27}$ Homolle and Querenne, op. cit., note 20 above.

A.R. Cushny, A textbook of pharmacology and therapeutics, 3rd ed., London, Rebman, 1904, p. 456.

Schick and Scheuer, op. cit., noe 24 above.

${ }^{30}$ W. Einthoven, 'Über die Deutung des Electrocardiograms', Pflügers Arch. ges. Physiol., 1913, 149:

31 Thomas Lewis, Lectures on the heart, New York, Hoeber, 1915.

${ }^{32}$ Cushny, op. cit., note 28 above, pp. 457-458.

${ }^{33}$ Thomas Lewis, Diseases of the heart, London, Macmillan, 1933, pp. 86-87.
} 65-86. 


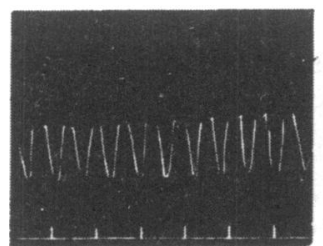

a

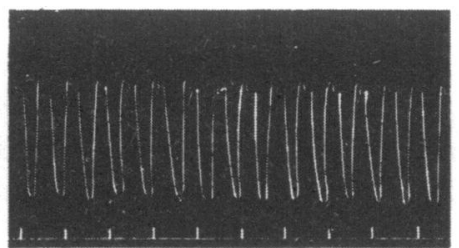

$b$

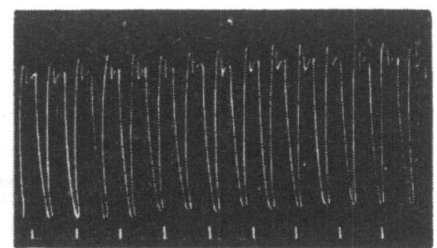

C

Figure 1. The effects of digitalis on intraventricular pressure in a dog heart. Panel $a$ shows a control record while $b$ and $c$ were obtained after infusing digitalis. The record is reproduced from Cushny (op cit., footnote 23, p. 100) and was originally obtained by François Franck in 1894.

evidence, maintained that the main value of glycosides was to rest the heart during the diastolic period. ${ }^{33}$

In the first edition of his book, Cushny made no special claims for digitalis in the various types of cardiac failure which were recognized at that time. However, the situation changed quickly when atrial (or auricular) fibrillation was recognized clinically by various figures at the beginning of the century ${ }^{34}$ and confirmed with electrocardiographic evidence by Lewis (1912) ${ }^{35}$ Atrial fibrillation was shown to complicate 60-70 per cent of the cases of cardiac failure presenting at that time. Thus, in 1910 , Wenckebach gave the following vivid account of the value of digitalis. ${ }^{36}$

\begin{abstract}
Among the drugs used for many years there is none perhaps more relied upon, more rightly trusted to, than digitalis. No practitioner ever failed to see its marvellous effects in appropriate cases .... What everyone knows about digitalis is, that in cases of heart failure with a small and weak pulse, quick and irregular rhythm, with dilation of its chambers, overfilling of the veins, dysuria and dropsy, it works wonderfully, slows and steadies the heart, raises the blood pressure, aids diuresis and drains the dropsical limbs. We know that in some cases, not well defined yet, it loses its beneficial effects, or even may do harm; that in large doses or if given for too long a time it accumulates in the body and causes symptoms of poisoning. So we give it as Withering did 125 years ago, until a desirable effect is reached, certainly stop it as soon as any inconvenience of its use might appear.
\end{abstract}

This is a clear expression of the view that digitalis is most effective in patients with atrial fibrillation (fast, irregular pulse). Wenckebach also introduced the idea, which has stimulated much research in this century, that it should be possible to define more closely the categories of patients for whom the cardiac glycosides are relatively effective and ineffective.

The careful case studies of Mackenzie, published in the same year as Wenckebach's paper, also led to the conclusion that digitalis was much more effective in heart failure with atrial fibrillation than when sinus rhythm was present. ${ }^{37}$ Mackenzie found that cases of heart failure who were in normal rhythm generally had relatively mild symptoms, responded well to bed rest, and showed little if any response to digitalis. It may be that the mild degree of failure in those with sinus rhythm in his study disguised any benefical effect of digitalis. Mackenzie's findings

${ }^{34}$ A.R. Cushny and C.W. Edmunds, Paroxysmal irregularity of the heart and auricular fibrillation, Studies in Pathology, Aberdeen University, 1912, pp. 95-110.

${ }^{35} \mathrm{~T}$. Lewis, 'Evidence of auricular fibrillation treated historically', Br. med. J., 1912, i: 57-60.

${ }^{36}$ K.F. Wenckebach, 'Discussion on the effects of digitalis on the human heat', ibid., 1910, ii: 1600-1610.

${ }^{37}$ James Mackenzie, 'Digitalis', Heart, 1911, 2: 273-386. 


\section{Susan Wray, D. A. Eisner, and D. G. Allen}

led him to the view that the rapid ventricular rate was a major factor causing heart failure. Lewis endorsed this view, stating "Those who regarded digitalis as a cardiac stimulant mistake its character: its chief action is to rest the heart. To the heart the foxglove is not a tonic but powerfully hypnotic. It controls the diastoles of the heart, it extends the period of sleep." ${ }^{\text {s8 }}$ The view that digitalis has little value in the treatment of heart failure in sinus rhythm appears in the influential textbooks of Mackenzie $(1916)^{39}$ and Lewis (1933). ${ }^{40}$ Why these two central figures in British cardiology chose to ignore the mounting evidence which contradicted this view is not entirely clear. McMichael points out that by this time both were moving into different fields and their interest in the recent advances in cardiology seemed to have been in decline ${ }^{41}$ Evidence for an effective action of cardiac glycosides in cardiac failure with sinus rhythm had been demonstrated in many studies, e.g. Janeway (1913), ${ }^{42}$ Christian (1921), ${ }^{43}$ Luten (1924) ${ }^{44}$ and Marvin (1927).${ }^{45}$ Many of the earlier studies were reviewed by Gavey and Parkinson (1939), ${ }^{46}$ and their own results were typical. They compared the responses to digitalis of two groups of patients in heart failure, forty-seven with sinus rhythm and thirty with atrial fibrillation. Cardiac failure was diagnosed on the basis of dyspnoea, liver enlargement, pleural effusions, and peripheral oedema, and improvement with digitalis was assessed by regression of these symptoms and signs. Both groups showed comparable improvement in a preliminary period of bed rest. On subsequent treatment with digitalis, 60 per cent of the patients with sinus rhythm improved while 72 per cent with atrial fibrillation improved. However, the proportion of patients showing "great improvement" was only 12 per cent in sinus rhythm but 28 per cent in atrial fibrillation. Thus, their study shows both that digitalis has a substantial beneficial effect in sinus rhythm but that the response in atrial fibrillation is greater. Note that there are substantial numbers of patients in both groups who do not appear to respond.

The debate about the role of cardiac glycosides in heart failure with sinus rhythm is still unresolved. ${ }^{47}$ Every authority recommends glycosides in heart failure when atrial fibrillation is present. There is much more variability in the recommendations for patients with failure who are in sinus rhythm. Many authorities make no distinction on the basis of the cardiac rhythm e.g., Goodman and Gilman, ${ }^{48}$ Hurst. ${ }^{49}$

${ }^{38}$ Thomas Lewis, 'On the cardinal principles in cardiological practice', Br.med.J., 1919, ii: 621-625.

${ }^{39}$ Sir James Mackenzie, Principles of diagnosis and treatment in the heart affections, London, Frowde, Hodder \& Stoughton, 1916, p. 240.

${ }^{40}$ Lewis, op. cit., note 31 above, p. 32.

${ }^{41}$ Sir John McMichael, $A$ transition in cardiology: the Mackenzie Lewis era. Harveian Oration 1975, London, Royal College of Physicians, 1976.

${ }^{42}$ T.C. Janeway, Trans. 17th Internat. Congress Medicine, London, 1913.

${ }^{43}$ H.A. Christian, 'Digitalis effects in chronic cardiac cases with regular rhythm in contrast to auricular fibrillation', Med. Clin. N. Amer., Phila., 1921/22, 5: 1173-1190.

44 D. Luten, 'Clinical studies with digitalis', Arch. int. Med., 1924, 33: 257-278.

${ }^{45}$ H.M. Marvin, 'Digitalis and diuretics in heart failure with regular rhythm, with special reference to the importance of etiological classification of heart disease', J.clin.Invest., 1927, 3: 521-539.

${ }^{16}$ C.J. Gavey and John Parkinson, 'Digitalis in heart failure with normal rhythm', Br. Heart J., 1939, 1: 27-44.

${ }^{47}$ A. Guz and D. McHaffie, 'The use of cardiac glycosides in sinus rhythm', Clin. Sci. \& Mol. Med., 1978, 55: 417-421.

${ }^{48}$ L.S. Goodman and A. Gilman, The pharmacological basis of therapeutics, 5th ed., New York, Macmillan, 1975, p. 676.

49 J.W. Hurst, The heart, 5th Ed., New York, McGraw-Hill, 1982. 


\section{Two hundred years of the foxglove}

Others recommend diuretics as the first line of treatment and a cardiac glycoside as a second, e.g. Hamer ${ }^{50}$ This view reflects the fact that diuretics invariably reduce oedema and are relatively free of serious side-effects whereas the cardiac glycosides are not uniformly effective and the side-effects are undeniably frequent and can be life-threatening. Uncertainty about the value of glycosides is often resolved by recommending a trial of digitalis and maintaining it only in those patients who show clear benefit.

\section{The long-term value of cardiac glycosides}

A subsidiary argument has developed on the question of whether digitalis should be maintained in the long term. In the past, it has been standard teaching that where digitalis has been effective in the treatment of chronic heart failure then it should be continued indefinitely. ${ }^{51}$ This view was questioned by Gold, who suggested that "only about $15 \%$ of cardiac patients owe to the habitual use of digitalis the fact that they are able to carry on with a reasonable degree of comfort". ${ }^{52}$ This provoked a short but convincing study by Rogen, who withdrew digitalis from twenty patients with established but controlled failure..$^{53}$ Sixteen of these showed objective signs of increasing failure (oedema, cyanosis, tachycardia, or visible dyspnoea), which appeared on average after five weeks. The remaining four showed subjective signs of increased failure (fatigue, dyspnoea on exercise) and were given a placebo. Their symptoms did not respond to the placebo and all four subsequently developed objective signs. Thus every patient eventually relapsed. However, all but two of these patients had atrial fibrillation, so that this study confirmed the value of long-term digitalis therapy in atrial fibrillation but did not address the issue for patients with sinus rhythm.

Studies in the last decade have increasingly questioned the value of long-term glycoside therapy for patients in sinus rhythm. A trial by Fleg et al. examined this issue using the full range of modern clinical trial techniques. ${ }^{54}$ Thirty patients with established heart failure who were in sinus rhythm entered the trial. At entry all patients were on maintenance glycoside therapy and the majority were using a diuretic. The presence of compensated heart failure was established from clinical symptoms, limitation of exercise capacity, and investigations of cardiac function. Then for a three-month period the digitalis was either replaced by a placebo or continued at the original dose, though neither the patients nor the doctors directly involved knew which category particular patients belonged to. The other medications were not changed during this period. In a second three-month period, the placebo and the digitalis were reversed. The general result was that withdrawal of digitalis had no significant effect on symptoms or exercise tolerance though some

\footnotetext{
50 John Hamer, 'The modern management of congestive heart failure', in D.J. Rowlands (editor), Recent advances in cardiology, London, Churchill Livingstone, 1984, vol. 9, pp. 275-288.

${ }^{51} \mathrm{Guz}$ and McHaffie, op. cit., note 47 above.

52 H. Gold, 'Digitalis, its action and usage', Med.Ann.DC, 1941, 10: 127-133.

${ }^{53}$ A.S. Rogen, 'Maintenance treatment with digitalis', Br.med.J., 1943, it: 694-695.

54 J.L. Fleg, S.H. Gottlieb, and E.G. Lakatta, 'Is digoxin really important in treatment of complicated heart failure. A placebo-controlled crossover study of patients with sinus rhythm',Amer.J.Med., 1982, 73: 244-250.
} 


\section{Susan Wray, D. A. Eisner, and D. G. Allen}

measures of cardiac function showed small but significant deterioration when digitalis was withdrawn.

However, other trials on this issue have given more complicated results. Griffiths et al. studied eleven patients in heart failure who were in sinus rhythm. ${ }^{55}$ When cardiac glycosides were stopped, one patient showed a pronounced deterioration which rapidly responded to restarting the glycosides: the others were unaffected. These authors reviewed trials on this question and noted that in 341 patients from 10 trials, 16 per cent deteriorated on stopping long-term glycoside treatment. Thus, while many patients can obviously manage without glycosides, there appears to exist a minority who do benefit in the long term. The characteristics of this group remain to be defined; conceivably, they are simply those with the most serious underlying pathology. Griffiths et al. also made the point that most of the trials have shown significant deterioration of cardiac function but this was often unaccompanied by changes in clinical symptoms or signs. The explanation for this finding may rest with the observation that, while cardiac glycosides increase the inotropic state in the presence or absence of cardiac failure, the glycosides only augment cardiac output when cardiac failure is present. Presumably, cardiac output is normally controlled by homeostatic mechanisms and provided cardiac output is within the normal range, an increase in inotropic state produced by a drug is counteracted by a reduction in sympathetic drive.

RESEARCH ON THE MECHANISM OF ACTION OF DIGITALIS IN THE TWENTIETH CENTURY Before describing more recent ideas on the mechanism of action of digitalis it is necessary to review current ideas concerning the mechanism of contraction of cardiac muscle. Contraction in cardiac muscle depends ultimately on the relative movements of two proteins: actin and myosin. Energy for this is provided by the hydrolysis of adenosine triphosphate (ATP). The principal signal which activates contraction is a rise of the intracellular calcium concentration $\left(\left[\mathrm{Ca}^{2+}\right]_{i}\right)$ from about 0.1 to $5 \mu \mathrm{M}$ and therefore the regulation of the contraction of cardiac muscle depends primarily on the regulation of $\left[\mathrm{Ca}^{2}\right]_{i}$. It is generally thought that, during the heartbeat, the calcium required for contraction is released from an intracellular store, the sarcoplasmic reticulum (s.r.). Relaxation of the heart is produced by the reuptake of $\mathrm{Ca}$ ions back into the s.r. The amount of calcium in the s.r. and ultimately therefore the amount that can be released to activate contraction depends on $\left[\mathrm{Ca}^{2+}\right]_{i}$, which is much less than extracellular calcium concentration. This concentration gradient produces a passive influx of $\mathrm{Ca}$ ions into the cell, which is opposed by an active extrusion of $\mathrm{Ca}$ ions. One mechanism for producing this is the sodium-calcium ( $\mathrm{Na}-\mathrm{Ca}$ ) exchange, which uses the energy provided by $\mathrm{Na}$ ions entering the cell down their electrochemical gradient to expel the $\mathrm{Ca}$ ions from the cell. Consequently, the level of $\left[\mathrm{Ca}^{2}+\right]_{i}$ and ultimately force will depend on the transmembrane Na gradient. The intracellular $\mathrm{Na}$ concentration is normally maintained at a low level by the sodium-potassium ( $\mathrm{Na}-\mathrm{K})$ pump and therefore anything which affects the activity of this pump will ultimately affect contraction.

\footnotetext{
${ }^{55}$ B.E. Griffiths, W.J. Penny, M.J. Lewis, and A.H. Henderson, 'Maintenance of the inotropic effect of digoxin on long-term treatment', Br.med.J., 1982, 284: 1819-1822.
} 


\section{Two hundred years of the foxglove}

As mentioned above, by 1900 , it had been shown that digitalis could increase the force of contraction of the isolated heart. It was not, however, until 1938 that Cattell and Gold showed that ouabain could increase the force of contraction of an isolated, electrically stimulated, cat papillary muscle.$^{56}$ One of their records is shown in fig. 2. As they pointed out, this experiment eliminated problems present in whole-heart studies where it was difficult to control for effects on coronary blood flow, cardiac size, and heart rate. Work in the twentieth century has therefore turned to the mechanism of the increased cardiac contractility.
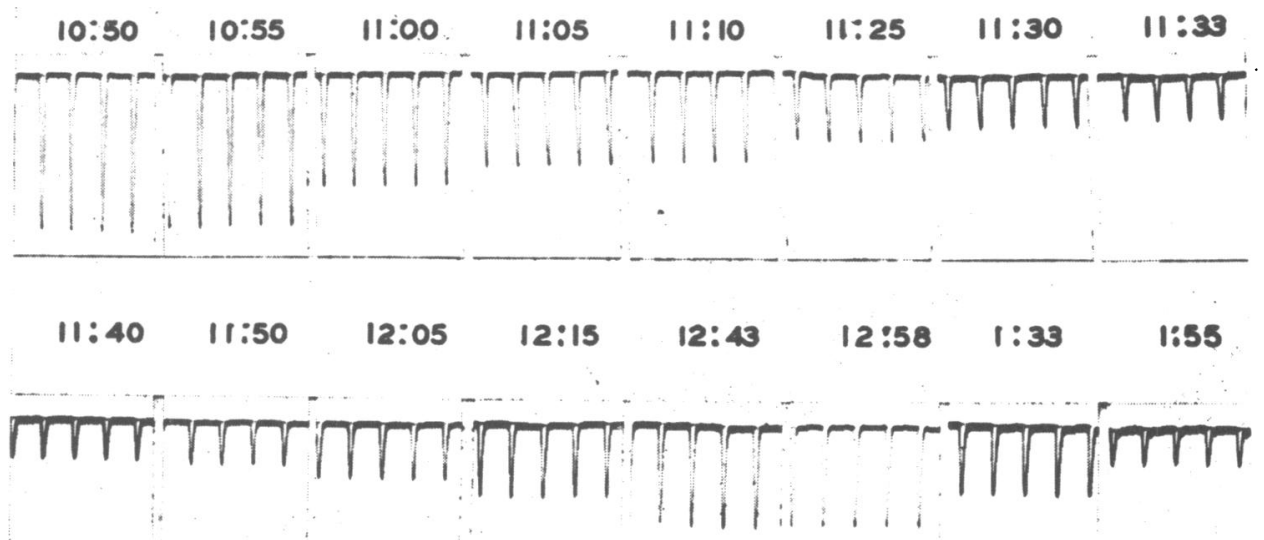

Figure 2. The effects of ouabain on an isolated cat papillary muscle. The downward deflections show the contractions of the muscle elicited by electrical stimulation at the times indicated. Note that, after beginning the experiment, the developed force gradually fell spontaneously. The addition of ouabain (at $11: 34)$ produced an increase of tension which eventually decayed away as the toxic effects of the drug developed.Record taken from Cattell and Gold (1938), see footnote 56.

In 1910, Straub suggested that digitalis acted as a surface active agent and that this reduction of surface tension somehow improved the contractility of the heart. ${ }^{57}$ However, Clark showed that substances which had much stronger surface-active properties did not increase the force of contraction of the heart. ${ }^{58}$ Instead, he noted that the actions of strophanthin are similar to those alkalis. Daly and Clark commented that the effects of digitalis could be mimicked by perfusing the heart with a solution of reduced sodium content. ${ }^{59}$ This observation accords well with modern ideas that the primary action of digitalis is to decrease the transmembrane gradient of $\mathrm{Na}$ ions (see below) but, at the time, there was no explanation of the result. It was also noted that the effects of digitalis depended on the presence of calcium in the perfusing solution, and both Burridge ${ }^{60}$ and Loewi ${ }^{61}$ suggested that $\mathrm{Ca}$ ions might be

${ }^{56} \mathrm{M}$. Cattell and H. Gold, 'The influence of digitalis glycosides on the force of contraction of mammalian cardiac muscle', J.Pharmacol.exp.Ther., 1938, 515: 221-235.

${ }^{57} \mathrm{~W}$. Straub, 'Quantitätive Untersuchungen über den Chemismus der Strophanthinwirkung', Biochem.Zt., 1910, 28: 392-406.

ss A.J. Clark, 'The mode of action of strophanthin upon cardiac tissue',J.Pharmacol.exp.Ther., 1914, 5: 215-234.

${ }^{59}$ I. de B. Daly and A.J. Clark, 'The action of ions upon the frog's heart',J. Physiol., 1921, 54: 367-383.

on W. Burridge, 'Researches on the perfused heart, some factors of the cardiac mechanism illustrated by reference to certain actions of barium and digitalis', Quart.J.Med., 1915, 43: 271. 
involved in the effects of digitalis and, in particular, that glycosides might activate the calcium of the heart or sensitize the muscle to calcium. In the light of subsequent work which showed the importance of calcium in muscle contraction, this view seems far-sighted. It should, however, be noted that it was based on little other than the fact that both calcium and digitalis increase contraction. It is, therefore, easy to understand Cushny, who described this as a "shadowy thesis". ${ }^{62}$

Since 1930, many hypotheses have been produced for the mechanism of action of the cardiac glycosides, a result of the explosion of work on cell biochemistry and physiology during this period. Indeed, at one time or another, digitalis has been suggested as affecting most stages in the mechanism of cardiac contraction. We will now review some of the suggested mechanisms. (i) Much work had been performed on the control of metabolism and cellular respiration, and it was suggested that the glycosides might act by affecting the energy metabolism of cardiac muscle. In support of this hypothesis, it was found that the concentrations of various metabolites were affected by digitalis. However, it was impossible to exclude the possibility that this was secondary to some other effect rather than being the cause of the positive inotropic action. Certainly, no effect of digitalis could be found on either isolated mitochondria or enzymes. ${ }^{33}$ (ii) It was suggested that cardiac glycosides might act by affecting the contractile proteins directly. Robb and Mallov showed that ouabain increased the shortening of actomyosin which was produced by ATP. ${ }^{64}$ Subsequent work even found that the effects of various glycosides on the thixotropy (the decrease of viscosity produced by stirring) of cardiac actomyosin correlated with their biological potency. ${ }^{65}$ However, this observation has not been confirmed, and this explanation has fallen into disrepute. (iii) The intracellular ionic concentrations of muscle cells are very different from those in the surrounding plasma and, in particular, the intracellular concentrations of $\mathrm{Na}$ and $\mathrm{K}$ are respectively less and greater than those in plasma. It was, therefore, of interest to see whether cardiac glycosides affected the intracellular concentrations of various ions. Harrison et al. found that the intracellular $\mathrm{K}$ concentration was decreased by digitalis therapy ${ }^{66}$ However, other workers found that digitalis, especially if applied in therapeutic rather than toxic concentrations, could increase intracellular K. Hajdu and Leonard suggested that the inotropic effects of $K$ loss might be produced by a loss of potassium from the cell. ${ }^{67}$ (iv) It was also suggested that cardiac glycosides could affect the "relaxing factor" of cardiac muscle. This relaxing factor is now known to be the

\footnotetext{
61 O. Loewi, 'Über den Zusammenhang zwischen Digitalis- und Kalziumwirkung', Arch.exp.Path.Pharmac., 1918, 83: 366.

${ }^{62}$ Cushny, op. cit., note 23 above p. 93.

${ }^{63} \mathrm{~A}$. Wollenberger, 'The energy metabolism of the failing heart and the metabolic action of the cardiac glycosides', Pharmacol.Rev., 1949, 1: 311-352.

'J.S. Robb and S. Mallov, 'Effect of ouabain on actomyosin threads', J.Pharmacol.exp.Ther., 1953, 108: 251-259.

${ }^{65}$ P. Waser, 'Cardiac glycosides and actomyosin', Proc. 1st Internat. Pharmacol. Meeting, 1961, 3: 173-184.

66 T.R. Harrison, Failure of the circulation, 2nd ed., Baltimore, Md., Williams \& Wilkins, 1939.

${ }^{67}$ S. Hajdu and E. Leonard, 'The cellular basis of cardiac glycosides action', Pharmacol.Rev., 1959, 11: 173-209.
} 


\section{Two hundred years of the foxglove}

uptake of $\mathrm{Ca}$ ions into the s.r. Lee et al. ${ }^{68}$ suggested that this might be affected by glycosides, although other work has shown contradictory effects of digitalis on it. ${ }^{89}$

The modern chapter in the history of digitalis owes its origin to three important breakthroughs. (i) In 1953, Schatzmann showed that cardiac glycosides inhibited the active uptake of $\mathrm{K}$ and extrusion of $\mathrm{Na}$ from red blood cells. ${ }^{70} \mathrm{The}$ importance of this experiment is that, in this simple preparation, digitalis has no effects on metablolism and therefore the effects on ion movements are not merely secondary to changes of metabolism. (ii) In 1945, Heilbrun and Wiercinski had shown that intracellular injection of calcium into skeletal muscle produced contraction. ${ }^{71}$ Subsequent work has confirmed that the application of calcium (but not other ions) produces contraction and, more recently, it has become possible to measure $\mathrm{Ca}$ during contraction in cardiac muscle and show that it rises. ${ }^{72}$ The record of fig. 3 shows that $\left[\mathrm{Ca}^{2}\right]_{\mathrm{i}}$ does, indeed, rise during the positive inotropic effects of the digitalis-like compound strophanthidin. (iii) The link between, on the one hand, the demonstration that digitalis inhibited $\mathrm{Na}$ and $\mathrm{K}$ movements and, on the other, that changes of intracellular $\mathrm{Ca}$ rather than $\mathrm{Na}$ or $\mathrm{K}$ were required to affect contraction was provided by work on the interactions between $\mathrm{Na}$ and Ca movements. In 1948, Wilbrandt and $\mathrm{Koller}^{73}$ found that the force of contraction of the frog heart was regulated by the ratio of the extracellular $\mathrm{Na}$ to $\mathrm{Ca}$ concentrations and, ten years later, this was interpreted as a competition between $\mathrm{Na}$ and $\mathrm{Ca}$ ions for binding site to activate contraction. ${ }^{74} \mathrm{~A}$ further ten years later, Reuter and Seitz showed that the efflux of calcium ions from the mammalian heart depended on the presence of extracellular $\mathrm{Na}^{75}$ The next year, Baker et al. ${ }^{76}$ described an exchange of $\mathrm{Na}$ and $\mathrm{Ca}$ ions across the membrane of squid axon and pointed out that a similar $\mathrm{Na}-\mathrm{Ca}$ exchange in cardiac muscle could explain not only the fact that contraction was increased by decreasing the extracellular $\mathrm{Na}$ concentration, but also how a rise of intracellular $\mathrm{Na}\left([\mathrm{Na}]_{\mathrm{i}}\right)$ resulting from $\mathrm{Na}-\mathrm{K}$ pump inhibition would act on $\mathrm{Na}-\mathrm{Ca}$ exchange to increase intracellular $\mathrm{Ca}$ and thence contraction:

digitalis $\rightarrow$ inhibit Na-K pump $\rightarrow \uparrow\left[\mathrm{Na}^{+}\right]_{\mathrm{i}} \stackrel{\mathrm{Na}-\mathrm{Ca} \text { exchange }}{\longrightarrow} \uparrow\left[\mathrm{Ca}^{2+}\right]_{\mathrm{i}} \uparrow$ tension

\footnotetext{
${ }^{88} \mathrm{~K}$.S. Lee, 'Relation of Ca ions to the inotropic and metabolic actions of cardiac glycosides', in op. cit., note 65 above, pp. 185-201.

${ }^{69} \mathrm{~K}$.S. Lee and W. Klaus, 'The subcellular basis for the mechanism of inotropic action of cardiac glycosides', Pharmacol.Rev., 1971, 23: 193-261.

${ }^{70}$ H.J. Schatzmann, 'Herzglykoside als Hemmstoffe für den activen Kalium- und Naturiumtransport durch die Erythrocytenmembran', Helv. physiol. pharmacol. Acta, 1953, 11: 346-354.

${ }^{71}$ L.V. Heilbrun and F.J. Wiercinski, 'The action of various cations on muscle protoplasm', J.cell.comp.Physiol., 1954, 29: 75.

${ }^{72}$ D.G. Allen and J.R. Blinks, 'Calcium transients in aequorin-injected frog cardiac muscle', Nature, 1978, 273: 509-513.

${ }^{73} \mathrm{~W}$. Wilbrandt and H. Koller, 'Die Calciumwirkung am Froschherzen als Funktion des Tonengleichgewichts zwischen Zellmembran und Umgebung', Helv. Physiol. pharmacol. Acta., 1948, 6: 208.

${ }^{74} \mathrm{H}$.C. Lüttgau and R. Niedergerke, 'The antagonism between $\mathrm{Ca}$ and $\mathrm{Na}$ ions on the frog's heart', J.Physiol., 1958, 143: ᄉ

${ }^{75} \mathrm{H}$. Reuter and $\mathrm{H}$. Seitz, 'The dependence of calcium efflux from cardiac muscle on temperature and ionic composition', ibid., 1968, 195: 451-470.

${ }^{76}$ P.F. Baker, M.P. Blaustein, A.L. Hodgkin, and R.A. Steinhardt, 'The influence of calcium on sodium efflux in squid axons', ibid., 1969, 200: 431-458.
} 
Susan Wray, D. A. Eisner, and D. G. Allen

$10 \mu M \quad$ strophanthidin
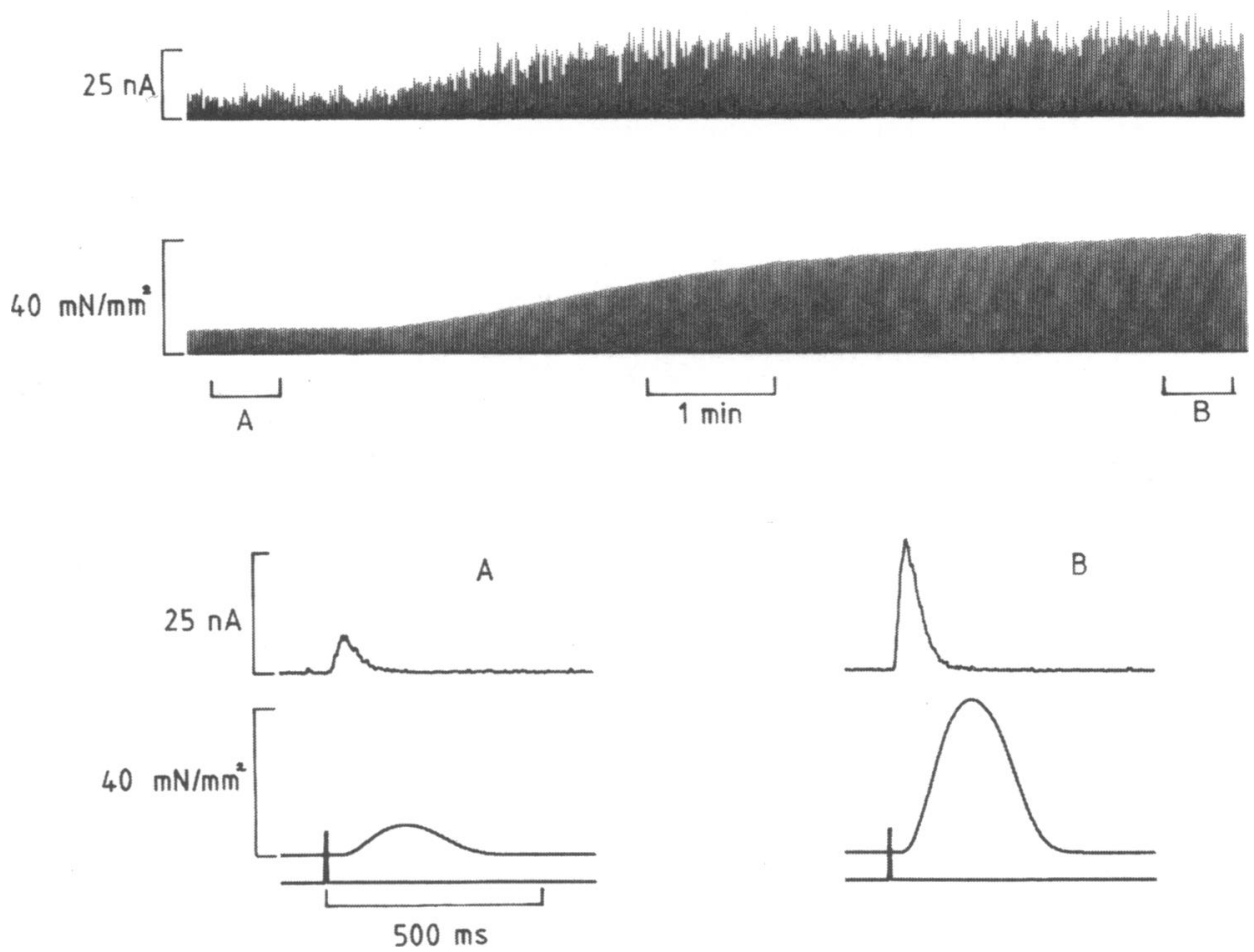

Figure 3. The effects of the cardiac glycoside strophanthidin on tension and intracellular calcium concentration $\left[\mathrm{Ca}^{2+}\right]_{i}$ in an isolated ferret papillary muscle. The top part of the figure shows the time course of onset of effects of stropanthidin. The upper trace is a record of the light emitted by the photoprotein aequorin. An increase of light emission indicates an increase of $\left[\mathrm{Ca}^{2+}\right]_{i}$. The lower trace is tension (upward deflection corresponds to an increase of tension). The muscle was stimulated every three seconds and, at the slow chart speed used, the increases of tension and $\left[\mathrm{Ca}^{2+}\right]_{i}$ produced by stimulation are fused together. The lower part of the figure shows averaged, expanded records from the regions indicated above. Note that strophanthidin increases both $\left[\mathrm{Ca}^{2+}\right]_{\mathrm{i}}$ and tension. (From D.G. Allen and C.H. Orchard, J. Mol. cell. Cardiol., 1984, 16: 117-128.)

Work in the period since 1969 has concentrated on testing this theory of Na-K pump inhibition. The theory has received support from the demonstration that manoeuvres which increase the intracellular $\mathrm{Na}$ concentration do increase the force of contraction of the heart. ${ }^{77}$ Objectors to this so-called sodium-lag theory question whether, at the concentrations used therapeutically, glycosides inhibit the Na-K pump. Uncertainty arises because of reports that, at low concentrations, the glycosides can stimulate the pump. Stimulation of the $\mathrm{Na}-\mathrm{K}$ pump has been reported

${ }^{77}$ D.A. Eisner, W.J. Lederer, and R.D. Vaughan-Jones, 'The dependence of sodium pumping and tension on intracellular sodium activity in voltage-clamped sheep Purkinje fibres', ibid., 1981, 317: 163-187. 


\section{Two hundred years of the foxglove}

as long ago as 1961 by Wilbrandt and Weiss, who found that, although high concentrations of cardiac glycosides inhibited, low concentrations increased the transport of $\mathrm{Na}$ ions across frog skin. ${ }^{78}$ Subsequently, Repke found that low concentrations of glycosides could stimulate a purified Na-K ATPase preparation. ${ }^{79}$ Although this stimulatory effect has been often reported, there has been considerable reluctance to accept it. There are probably two reasons for this. First, the stimulatory effect is not always seen and, even in preparations in which it can be demonstrated sometimes, it is a labile phenomenon..$^{80}$ In contrast, the inhibitory effect (of high concentrations) is perfectly reproducible. Another unresolved question is whether the reported stimulation is a direct effect on the $\mathrm{Na}-\mathrm{K}$ pump or, alternatively, is produced by an action of the glycoside on nerve terminals which then produces a release of noradrenaline which can indirectly stimulate the Na-K pump. ${ }^{81}$ Second, even if stimulation could be shown consistently, there is no explanation for how a Na-K pump stimulation could increase the force of contraction. Indeed, on the model presented above, pump stimulation would be expected to decrease rather than to increase the force. It has therefore been suggested (see Noble ${ }^{82}$ for a review) that the inotropic effect of cardiac glycosides may depend on some other action than the direct effect on the Na-K pump rate To confuse the issue further, we would note that recent work (Isenberg) claims that intracellular injection of cardiac glycosides increases the force of contraction. ${ }^{83}$ Since binding of cardiac glycosides to the sodium pump occurs at the outside of the cell, this observation would suggest that the Na-K pump may not be directly involved in the inotropic action.

A lot of recent work has been directed to investigating the idea that there may be a naturally occurring endogenous cardiac glycoside in man. It has been reported that a substance isolated from plasma can inhibit the $\mathrm{Na}-\mathrm{K}$ pump and that this substance is present at greater concentrations in plasma from hypertensive patients. It has been suggested that such an endogenous cardiac glycoside would increase the contraction of arterial smooth muscle and thence increase blood pressure. It has therefore been suggested as one of the causes of essential hypertension. ${ }^{84}$

We would end this review by quoting from Glynn who, in 1969, summarized the problem in research on the mechanism of action of cardiac glycosides as follows: "The pharmacologist confronted with the actions of cardiac glycosides is a little like the medieval philosopher confronted with the universe. Many things happen and

\footnotetext{
${ }^{78} \mathrm{~W}$. Wilbrandt and E.M. Weiss, 'Antagonism between cardiac glycosides and corticosteroids in the frog's skin potential', Arzneimittelforsch., 1960, 10: 409.

${ }^{79} \mathrm{~K}$. Repke, 'Metabolism of cardiac glycosides', in op. cit., note 65 above, pp. 47-73.

${ }^{80}$ R.F. Palmer, K.C. Lasseter, and S.L. Melvin, 'Stimulation of $\mathrm{Na}^{+}$and $\mathrm{K}^{+}$dependent adenosine triphosphate by ouabain', Arch.Biochem., 1966, 113: 629.

${ }^{81}$ T.J. Hougen, N. Spicer, and T.W. Smith, 'Stimulation of monovalent cation active transport by low concentrations of cardiac glycosides. Role of catecholamines', J.clin.Invest., 1981, 68: 1207-1214.

82 D. Noble, 'Mechanism of action of therapeutic levels of cardiac glycosides', Cardiovasc.Res, 1980, 9: 495-541.

${ }^{83} \mathrm{G}$. Isenberg, 'Contractility of isolated bovine myocytes is enhanced by intracellular injection of cardioactive glycosides. Evidence for an intracellular mode of action', in E. Erdmann (editor), Cardiac glycoside receptors and positive inotropy, Darmstadt, Steinkopff, 1984, pp. 56-71.

84 J.M. Hamlyn and M.P. Blaustein, 'Endogenous digitalis-like compounds: putative regulators of the sodium pump', Trends in neurosciences, 1984, 307-308.
} 
Susan Wray, D. A. Eisner, and D. G. Allen

some things obviously happen as the result of other things, but identification of the first cause turns out to be rather difficult". ${ }^{85}$ This statement is still clearly relevant today.

\section{ACKNOWLEDGEMENTS}

S. Wray is grateful to Action Research-The National Fund for Research into Crippling Diseases, for financial support. We are also grateful to Dr G. Eisner for German translations.

s5 I.M. Glynn, 'The effects of cardiac glycosides on metabolism and ion fluxes', in Charles Fisch and Borys Surawicz (editors), Digitalis, New York, Grune \& Stratton, 1969, pp. 30-42. 